\title{
Bioequivalencia entre dos formulaciones de claritromicina en suspensión pediátrica existentes en el mercado chileno
}

LEONARDO GAETE G. ${ }^{1}$, OSCAR SCHATLOFF B. ${ }^{2}$, M. PIEDAD BELLO P. ${ }^{2}$, CRISTIÁN SERRANO A. ${ }^{2}$, VERÓNICA CEBALLOS N. ${ }^{2}$, FRANCO ANZIANI O.$^{2}$, JAIME SOLÍS G. ${ }^{3}$, PABLO VENEGAS F. ${ }^{4}$ e IVÁN SAAVEDRA S. ${ }^{1}$

\section{Bioequivalence evaluation of two brands of clarithromycin suspension available in the Chilean pharmacopeia}

A comparative bioavailability study was conducted in order to test the bioequivalence between two formulations of clarithromycin in suspension $250 \mathrm{mg} / 5 \mathrm{~mL}$, a local formulation (Pre-Clar $\AA$ ), and the original product (Klaricid®). In both cases, a single oral dose of $500 \mathrm{mg}$ was used. A microbiological assay was used to determine the antibiotic plasmatic concentrations. The assay is based on the correlation between the inhibition of bacterial growth in agar plates and the plasmatic concentration of clarithromycin. A total of twelve healthy young volunteers participated and completed the study protocol, which was approved by the local ethic committee. None of the pharmacokinetic parameters such as peak plamatic level $\left(\mathrm{C}_{\text {max }}\right)$, half-live $\left(\mathrm{t}_{1 / 2}\right)$, area under the curve of plasmatic levels vs time, from 0 to inifinity $\left(\mathrm{ABC}_{0 . \mathrm{y}}\right)$ and velocity rate constant $\left(\mathrm{K}_{\mathrm{abs}}\right)$, showed significant differences for both products. According to the guidelines recommended by the FDA and by means of our findings, we can assure that Pre-Clar ${ }^{\circledR}$ and Klaricid ${ }^{\circledR}$ in suspension are bioequivalents. Therefore, we may assume that both products are interchangeable without compromising clinical efficacy.

Key words: Clarithromycin; Suspension; Bioequivalence; Pharmacokinetics.

\section{Introducción}

La biodisponibilidad de un fármaco es la fracción de un fármaco que efectivamente llega a la circulación sistémica, y la velocidad con que se realiza este proceso ${ }^{1}$.

La biodisponibilidad relativa o bioequivalencia individual es una medida comparativa de la calidad de una formulación farmacéutica, en donde se compara un producto nuevo (en términos de la velocidad y la cantidad de principio activo que entrega) con el producto original (innovador del mercado), permitiendo estimar si dos formulaciones son similares o no, en relación con la velocidad y extensión en que son absorbidas ${ }^{2}$.
Por otra parte, la intercambiabilidad es el acto realizado por un médico de utilizar indistintamente una formulación u otra, disponiendo de elementos de juicio suficientes para asegurar que la calidad de uno de los productos farmacéuticos es comparable o similar a la del otro (alternativas farmacéuticas) ${ }^{3}$.

La claritromicina es un antimicrobiano macrólido de segunda generación, derivado semisintético de la eritromicina. Difiere de ésta solamente en la metilación del grupo hidroxilo en posición 6 del anillo lactónico. Suele ser bacteriostática, pero se ha demostrado capacidad bactericida contra microorganismos muy sensibles cuando la concentración del antimicrobiano es elevada ${ }^{4}$.

\footnotetext{
Facultad de Medicina, Universidad de Chile:

Programa de Farmacología Molecular y Clínica, ICBM.

Estudiante de Medicina Universidad de Chile.

Clínica Psiquiátrica.

Servicio de Neurología, Hospital Clínico.
}

Recibido: 9 septiembte 2002

Aceptado: 7 julio 2003 
Su biodisponibilidad es cercana al 60\%, alcanzándose la máxima concentración plasmática $\left(\mathrm{C}_{\text {máx }}\right)$ entre una y dos horas después de la administración oral. Entre el 20 y $40 \%$ de la dosis se excreta de forma inalterada en la orina y otro $10 \mathrm{a}$ $15 \%$ como 14- hidroxi metabolito. La vida media de eliminación $\left(\mathrm{t}_{1 / 2}\right)$ es de 3 a $7 \mathrm{~h}$ y de 5 a $9 \mathrm{~h}$ para la 14-hidroxiclaritromicina, su principal metabolito que también tiene actividad farmacológica ${ }^{8}$.

Este fármaco ha experimentado un uso creciente en la población pediátrica, especialmente en el tratamiento de las infecciones respiratorias altas y bajas, lo que ha traído consigo la aparición de nuevas formulaciones del fármaco en el mercado chileno. Esto hace necesario la realización de estudios de bioequivalencia, que permitan la caracterización de las propiedades farmacocinéticas de los productos nacionales en comparación con los productos innovadores. Para el caso de la claritromicina en su presentación de suspensión pediátrica $(250 \mathrm{mg} / 5 \mathrm{ml})$ no existen antecedentes en el medio nacional que permitan concluir cuáles productos pueden considerarse bioequivalentes respecto del producto innovador.

El objetivo de este trabajo fue desarrollar un estudio de biodisponibilidad relativa de una formulación nacional de claritromicina en suspensión de $250 \mathrm{mg} / 5 \mathrm{ml}$, respecto de la misma formulación del producto innovador. La formulación de referencia fue el producto original (Klaricid®) y el producto test fue una formulación similar conteniendo claritromicina (PreClar®).

\section{Material y Métodos}

Voluntarios. En el estudio participaron doce sujetos voluntarios sanos de sexo masculino, cuyas características antropométricas se resumen en la Tabla 1.

Todos los voluntarios fueron informados apropiadamente sobre la metodología a emplear durante el estudio, la duración de éste, los fines que se perseguían y los posibles efectos adversos que podrían presentarse durante el desarrollo del mismo. Una vez informados, decidieron su participación en el estudio, mediante consentimiento informado. A los voluntarios seleccionados se les sometió a un completo examen físico por parte de un médico cirujano, y a un conjunto de pruebas de laboratorio, las cuales no mostraron desviaciones significativas que pudiesen indicar patologías renales, hepáticas, cardíacas o gastrointestinales.

El protocolo del estudio fue aprobado por el Comité de Ética de la Facultad de Medicina de la Universidad de Chile. En todo momento se siguieron las recomendaciones para guiar los estudios en seres humanos, emanados de la declaración de Helsinki9.

El diseño del estudio fue doble ciego, randomizado y cruzado, administrándose $10 \mathrm{ml}$ de cada producto $(500 \mathrm{mg}$ ) a los voluntarios, en dos períodos separados por 14 días.

Productos farmacéuticos y procedimiento. Los productos farmacéuticos de claritromicina en

Tabla 1. Características antropométricas de los voluntarios

\begin{tabular}{lccc}
\hline $\mathbf{N}^{\circ}$ & Edad (años) & Peso $(\mathbf{k g})$ & Talla $(\mathbf{c m})$ \\
\hline 1 & 20 & 74 & 183 \\
2 & 19 & 78 & 178 \\
3 & 22 & 75 & 180 \\
4 & 20 & 51 & 165 \\
5 & 19 & 65 & 171 \\
6 & 19 & 81 & 178 \\
7 & 20 & 73 & 175 \\
8 & 19 & 75 & 175 \\
9 & 19 & 74 & 179 \\
10 & 18 & 81 & 174 \\
11 & 18 & 65 & 175 \\
12 & 18 & 68 & 171 \\
Promedio & 19 & 71,6 & 175,3 \\
DS* & 1 & 8,4 & 4,8 \\
\hline
\end{tabular}

* DS: desviación estándar 
suspensión de $250 \mathrm{mg} / 5 \mathrm{ml}$ utilizados (Klaricid $\AA$, Abbott Laboratories-producto A y Pre Clar®, Laboratorio Chile SA-producto B), fueron adquiridos en oficinas de farmacia y reconstituidos por uno de los investigadores, una hora antes de administrarlo, siguiendo las indicaciones de los respectivos fabricantes. Para cautelar el ciego, los productos se dispusieron en frascos de vidrio previamente esterilizados, rotulándose como "Producto A" o "Producto B". Los doce voluntarios concurrieron en ayunas, a las 6:30 horas de cada período del estudio. A cada voluntario se le sirvió un desayuno equilibrado estándar. Después de éste y según protocolo, cada voluntario recibió la forma farmacéutica $(10 \mathrm{~mL}$ del producto A ó $10 \mathrm{~mL}$ del producto B) con $200 \mathrm{~mL}$ de agua potable, bajo la estricta vigilancia de los investigadores. Posteriormente se procedió a extraer las muestras de sangre en los horarios preestablecidos (muestras a tiempo 0 (pre dosis), $1,2,3,4,5,6,8,10$ y 12 horas).

Las muestras sanguíneas fueron centrifugadas inmediatamente después de su obtención a 2.000 rpm durante 10 minutos a $4^{\circ} \mathrm{C}$, en una centrífuga clínica. El plasma obtenido fue almacenado a $-20^{\circ} \mathrm{C}$ hasta el momento del análisis.

Después de extraída la muestra de sangre correspondiente a las 6 horas a cada voluntario se le dio un almuerzo estándar. Dos horas después, cada voluntario recibió una merienda también estandarizada. A las once horas post administración del fármaco, se les dio una cena también estandarizada.

Dos semanas más tarde se realizó la segunda sesión, procediéndose al cruce de los probandos, es decir, los voluntarios que habían recibido el Producto A en la primera sesión, recibieron el Producto B y viceversa.

Todas las muestras fueron analizadas, dejándose una contra muestra almacenada a $-20^{\circ} \mathrm{C}$. La medición de la concentración de antimicrobiano en las muestras se realizó dentro de la misma semana en que fueron obtenidas. En el primer día de análisis se utilizaron las muestras correspondientes a los tiempos 0 (pre dosis), 1, 2, 3 y 4 h. Para el segundo día de análisis se utilizaron las muestras correspondientes a los tiempos 5, 6, 8, 10 y 12 horas.

Determinación de claritromicina en el plas$m a$. Se utilizó un método microbiológico estandarizado y adaptado en el Laboratorio de Farmacocinética de la Facultad de Medicina de la Universidad de Chile.

El método microbiológico utilizado en el presente trabajo para la determinación de niveles plasmáticos corresponde al protocolo de Pollini et $\mathrm{al}^{10}$. Dicho método se basa en la medición de halos de inhibición de crecimiento bacteriano que se producen al colocar sensidiscos impregnados con plasma de los voluntarios que han recibido el antimicrobiano en un medio de cultivo que contiene una cepa bacteriana sensible a dicho antimicrobiano; en este caso particular la cepa utilizada fue Micrococcus luteus ATCC 9341. Este método ha sido validado y es ampliamente aceptado para determinar concentraciones de antimicrobianos en fluidos biológicos ${ }^{11,12}$. Así, para mayores concentraciones plasmáticas del antimicrobiano se producirá un halo de inhibición mayor, y para concentraciones menores un halo menor.

Con los datos de tamaño del halo de inhibición de crecimiento bacteriano, se puede obtener la concentración plasmática de claritromicina. Para ello, se confecciona una curva de calibración, la cual es una relación entre una concentración conocida del analito, en este caso el antimicrobiano, y la respuesta que se obtiene a esta concentración, es decir, el diámetro del halo de inhibición obtenido para esa concentración.

\section{Análisis farmacocinético y estadístico.}

Los valores de $\mathrm{t}_{\text {máx }}$ y $\mathrm{C}_{\text {máx }}$ se obtuvieron por inspección directa de la curva de concentración plasmática versus tiempo de cada voluntario. Los parámetros farmacocinéticos: áreas bajo la curva (entre 0 y 12 horas), tiempo de vida media, el clearance corporal total y el volumen de distribución, se determinaron a través del programa computacional AUC-RPP ${ }^{13}$, el cual se basa en un análisis de regresión de la fase terminal, del área bajo la curva $(A B C)$ y del área bajo la curva en el primer momento. Los valores de los parámetros $\mathrm{C}_{\text {máx }}$ y $\mathrm{ABC}$ obtenidos para ambas formulaciones se expresaron en forma logarítmica y fueron sometidos a análisis de varianza (ANOVA). Se determinaron intervalos de confianza del $95 \%$ para la diferencia entre los promedios de los parámetros farmacocinéticos obtenidos con ambas formulaciones. Se estimaron como significativas aquellas diferencias en las que el valor de $\mathrm{p}$ fue menor que $0,05^{14}$.

\section{Resultados}

Durante el desarrollo del estudio no se presentaron dificultades en la administración de los tratamientos, cumpliendo todos los voluntarios en forma satisfactoria con el protocolo establecido. No hubo contratiempos con ninguna de las 


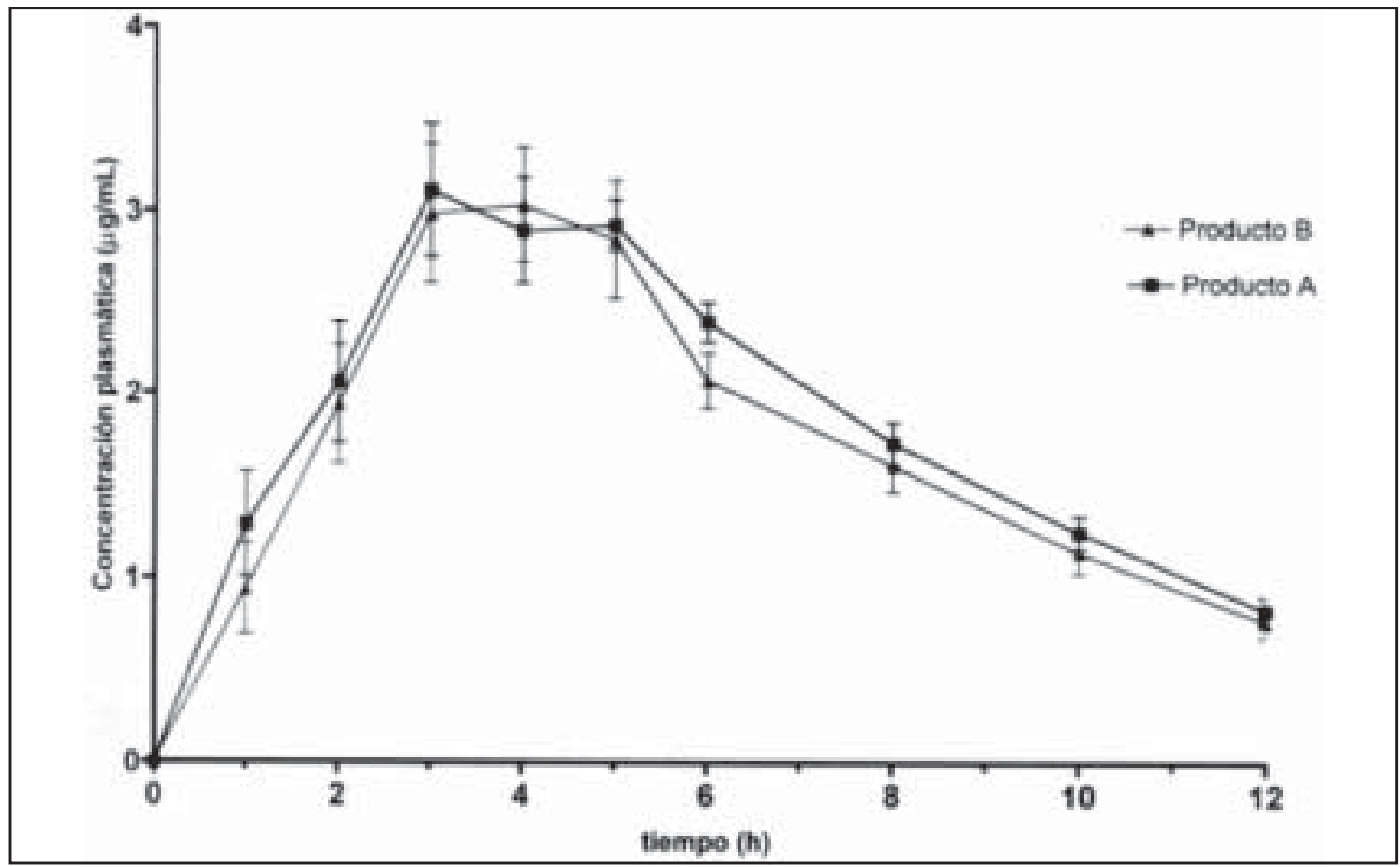

Figura 1. Concentraciones plasmáticas promedio de claritromicina obtenidas con dos productos del mercado nacional en 12 voluntarios sanos. Los 12 voluntarios recibieron $10 \mathrm{~mL}(500 \mathrm{mg})$ de claritromicina suspensión. Las concentraciones plasmáticas se determinaron mediante ensayo microbiológico de difusión en disco de papel. Cada punto representa el promedio de concentración con su desviación estándar.

muestras obtenidas, siendo por lo tanto, todas ellas sometidas a posterior análisis.

La técnica analítica de medición resultó ser bastante reproducible y sensible. Los valores del halo de inhibición para el estándar de referencia de $0,25 \mu \mathrm{g} / \mathrm{ml}$ fluctuaron entre 11 y $15 \mathrm{~mm}$.

A su vez, los controles de calidad empleados permitieron establecer que el coeficiente de variación del método fue en promedio de 9,2\% (rango: 5,4-13,2\%), observándose la mayor variabilidad con las concentraciones menores de $0,25 \mu \mathrm{g} / \mathrm{ml}$. En la Figura 1 se presentan las curvas promedio de concentración plasmática de claritromicina versus el tiempo transcurrido desde la administración de claritromicina en suspensión, hasta las doce horas, en los doce voluntarios. Ambas curvas exhiben la misma forma (ajustando a un modelo farmacocinético de un compartimento), con cinéticas de absorción y de eliminación de primer orden. La absorción puede caracterizarse como lenta, con un $\mathrm{t}_{\text {máx }}$ para ambas formulaciones cercano a las 4 horas, aun cuando ya después de una hora de la administración se alcanzan concentraciones plasmáticas efectivas. Las concentraciones máximas alcan- zadas también son comparables, con promedios de 3,67 y $3,57 \mu \mathrm{g} / \mathrm{ml}$ para A y B respectivamente. Análogamente, para el parámetro $\mathrm{ABC}$ de concentraciones plasmáticas, desde tiempo cero hasta las doce horas post administración, los valores alcanzados son muy similares: $22,6 \mathrm{y}$ $21,1 \mu \mathrm{g} \cdot \mathrm{h} / \mathrm{ml}$. Además, se encontró que los parámetros farmacocinéticos obtenidos con ambas formulaciones están en concordancia con los descritos en la literatura para este fármaco ${ }^{15}$.

En la Tabla 2 se presentan los parámetros farmacocinéticos promedio de tiempo de vida media $\left(\mathrm{t}_{1 / 2}\right)$, concentración plasmática máxima $\left(\mathrm{C}_{\text {máx }}\right)$, tiempo requerido para alcanzar la concentración plasmática máxima $\left(\mathrm{t}_{\text {máx }}\right), \mathrm{ABC}$ de concentraciones plasmáticas en el tiempo, desde el tiempo 0 hasta 12 horas, clearance total $(\mathrm{Cl} \mathrm{t}) \mathrm{y}$ volumen de distribución $(\mathrm{Vd})$ obtenidos con los productos A y B.

Al utilizar la prueba de ANOVA con un intervalo de confianza del $95 \%$, en la comparación de los parámetros farmacocinéticos obtenidos con ambos productos, no se encontró diferencias estadísticamente significativas para alguno de ellos. 
Tabla 2. Parámetros famacocinéticos promedio de claritromicina y su desviación estándar, en 12 voluntarios sanos, con dos formulaciones del fármaco en suspensión (dosis: $500 \mathrm{mg}$ )

\begin{tabular}{lrrr}
\hline Parámetro & Producto $\mathbf{A}$ & Producto B & P \\
\hline $\mathrm{C}_{\text {máx }}(\mu \mathrm{g} / \mathrm{ml})$ & $3,67 \pm 0,71$ & $3,57 \pm 1,03$ & 0,78 \\
$\mathrm{t}_{\text {máx }}(\mathrm{h})$ & $3,92 \pm 0,90$ & $4,08 \pm 1,00$ & 0,68 \\
$\mathrm{ABC}_{0-12}(\mathrm{mg} \times \mathrm{h} / \mathrm{ml})$ & $22,60 \pm 4,50$ & $21,10 \pm 6,70$ & 0,52 \\
$\mathrm{t}_{1 / 2}(\mathrm{~h})$ & $3,96 \pm 0,79$ & $4,14 \pm 1,09$ & 0,81 \\
$\mathrm{Vd}(\mathrm{L} / \mathrm{kg})$ & $1,50 \pm 0,30$ & $1,70 \pm 0,50$ & 0,24 \\
$\mathrm{Cl} \mathrm{t}(\mathrm{ml} / \mathrm{kg} / \mathrm{min})$ & $4,40 \pm 0,8$ & $4,90 \pm 1,30$ & 0,27 \\
\hline
\end{tabular}

$\mathrm{C}_{\text {máx }}=$ concentración plasmática máxima.

$\mathrm{t}_{\text {máx }}=$ tiempo requerido para alcanzar la $\mathrm{C}_{\text {máx }}$.

$\mathrm{ABC}_{0-12}=$ área bajo la curva de concentraciones plasmáticas versus tiempo, desde cero a 12 horas.

$\mathrm{t} 1 / 2=$ tiempo de vida media.

$\mathrm{Vd}=$ volumen de distribución .

$\mathrm{Cl} \mathrm{t}=$ depuración del fármaco.

\section{Discusión}

En este trabajo se realizó un estudio de biodisponibilidad relativa entre dos formulaciones farmacéuticas que contienen claritromicina. Para ello, a un mismo grupo de voluntarios sanos se les administró en forma cruzada $500 \mathrm{mg}$ de claritromicina, proveniente de dos formulaciones en suspensión que contienen $250 \mathrm{mg} / 5 \mathrm{ml}$ de claritromicina y que se expenden en el mercado chileno.

La FDA recomienda que para considerar bioequivalentes a dos productos farmacéuticos, éstos deben poseer la misma concentración de principio activo y la misma formulación (comprimidos, jarabe, cápsulas, suspensión, etc). Pero más importante aún es que los parámetros de $\mathrm{C}_{\text {máx }} \mathrm{y}$ de $\mathrm{ABC}$ obtenidos con ambos productos $\mathrm{y}$ expresados en forma logarítmica deben ser similares. El resto de los parámetros farmacocinéticos $\left(\mathrm{K}_{\mathrm{abs}}, \mathrm{T}_{1 / 2}, \mathrm{~K}_{\mathrm{el}}, \mathrm{Cl}, \mathrm{Vd}\right)$ ayudan a la mejor caracterización de los productos a comparar, pero no determinan la intercambiabilidad de los mismos.

Además, la FDA recomienda que para estudios de bioequivalencia, debe medirse solamente el fármaco parental y no el metabolito (claritromicina y 14-hidroxiclaritromicina en nuestro estudio). La base racional para esta recomendación es que el perfil de concentración versus tiempo del fármaco parental es más sensible a los cambios en la calidad de la formulación. La formación de metabolito por su parte, es el reflejo de la cantidad de fármaco parental que ingresó al organismo y que es biotransformado.

Cuando dos productos farmacéuticos tienen una biodisponibilidad comparable, reflejada por una $\mathrm{ABC}$ y $\mathrm{C}_{\text {máx }}$, dentro de rangos muy definidos, se considera que ellos son bioequivalentes. De esto se deduce que son alternativas farmacéuticas intercambiables y bajo las recomendaciones de la comisión de medicamentos de la OMS, la copia debe recibir el nombre de producto genéri$\mathrm{co}^{16}$.

De acuerdo a nuestros resultados, podemos afirmar que ambas formulaciones de claritromicina en suspensión son bioequivalentes, ya que no se observaron diferencias estadísticamente significativas para ninguno de los parámetros farmacocinéticos determinados en este estudio.

Puesto que, este estudio fue realizado en voluntarios sanos, no puede tomarse como evidencia para utilizar una u otra formulación con fines terapéuticos. Conclusiones acerca de la efectividad clínica de las formulaciones utilizadas en el presente estudio, no pueden obtenerse a partir de los datos aquí presentados. La evidencia aquí presentada, señala claramente que con ambos productos se obtienen concentraciones plasmáticas y áreas bajo la curva estadísticamente iguales, y por lo tanto pueden considerarse bioequivalentes.

\section{Resumen}

Se realizó un estudio comparativo de biodisponibilidad, para evaluar la bioequivalencia entre dos formulaciones de claritromicina en suspensión de $250 \mathrm{mg} / 5 \mathrm{~mL}$, una nacional (Pre-Clar ${ }^{\circledR}$ ), y el innovador del mercado (Klaricid $\left.{ }^{\circledR}\right)$. En ambos casos, se administró una dosis de $500 \mathrm{mg}$. Se utilizó un ensayo microbiológico para determinar las concentraciones plasmáticas del 
antimicrobiano. El ensayo está basado en la correlación entre la inhibición del crecimiento bacteriano y la concentración plasmática de claritromicina. Un total de 12 voluntarios, jóvenes sanos, participaron y completaron el protocolo del estudio, el cual fue aprobado por el Comité de Ética de la Facultad de Medicina de la Universidad de Chile. Los parámetros farmacocinéticos de concentración plasmática máxima $\left(\mathrm{C}_{\text {máx }}\right)$, tiempo de vida media $\left(\mathrm{t}_{1 / 2}\right)$, área bajo la curva concentraciones plasmáticas versus tiempo, desde cero a infinito $\left(\mathrm{ABC}_{0-\not}\right)$ y la constante de velocidad de absorción $\left(\mathrm{K}_{\mathrm{abs}}\right)$, no mostraron diferencias estadísticamente significativas entre los productos utilizados. De acuerdo a los criterios recomendados por la FDA y sobre la base de nuestros resultados, se concluye que las formulaciones en suspensión pediátrica de $250 \mathrm{mg} / 5 \mathrm{~mL}$ Pre-Clar ${ }^{\circledR}$ y Klaricid ${ }^{\circledR}$ son bioequivalentes asumiéndose que tendrán igual eficacia clínica.

\section{Bibliografía}

1.- FDA: Guidance for Industry. Bioavailability and bioequivalence studies for orally administered drug products - General Considerations. October 2000.

2.- FDA: Guidance for Industry. In vivo Bioequivalence Studies Based on Population and Individual Bioequivalenece Approaches. October 1997.

3.- FDA: Guidance for Industry. Average, Population, an Individual Approaches to Establishing Bioequivalence. August 1999.
4.- Kapusnik-ulner J, Sande M, Chambers H. Las bases farmacológicas de la terapéutica. Capítulo 47, novena edición 1996.

5.- Al-assi M, Ramírez F, Lew G, Genta R, Graham D. Clarithromycin, tetracycline, and bismuth: a new nonmetronidazole therapy for Helicobacter pylori infection. Am J Gastroenterol 1994; 89: 1203-5.

6.- CDC. Recommendations on prophylaxis and therapy for disseminated Mycobacterium avium complex for adults and adolescents infected with human inmunodeficiency virus. 1993 c; 42: RR-9, 17-20.

7.- CDC. Sexually transmitted diseases treatment guidelines. 1993b; 42: RR-14, 1-102

8.- Fraschini F, Scaglione F, Demartini G. Clarithromycin clinical pharmacokinetics. Clin Pharmacokinet 1993; 25: $189-204$.

9.- Declaración de Helsinki. Documentos sobre ética médica, Colegio Médico de Chile AG; Grupos comunicacionales, 1986: 91-5.

10.- Pollini R, Lettieri B, Nanney M. Assay microbiological: clarithromycin in plasma-paper disc method. Protocolo $\mathrm{N}^{\circ}$ w96-124, ABBOTT Laboratories, Argentina 1996.

11.- Coleman M R, Peloso J S, Moran JW. Microbiological plate assay for determination of tilmicosin in bovine serum. JAOAC Int 1995; 78: 659-62.

12.- Breier A R, García C V, Oppe T P, Steppe M, Schapoval E E. Microbiological assay for azithromycin in pharmaceutical formulations. J Pharm Biomed Anal 2002; 29: 957-61.

13.- Ritschell W. AUC-RPP basic computer program for compartment model independent pharmacokinetic analysis. Meth Find Exptl Clin Pharmacol 1986; 8: 633-40.

14.- FDA: Guidance Statistical Approaches to establishing Bioequivalence. February 2001.

15.- AHFS. Drug information. 1996. Pág. 231.

16.- Arias T. Glosario de Medicamentos $1^{\circ}$ Edición OPS/ OMS, 1999.

Correspondencia a:

Leonardo Gaete $\mathrm{G}$.

E-mail: lgaete@machi.med.uchile.cl 